(C) Society for Benefit-Cost Analysis, 2018. This is an Open Access article, distributed under the terms of the Creative Commons Attribution licence (http://creativecommons.org/licenses/by/4.0/), which permits unrestricted re-use, distribution, and reproduction in any medium, provided the original work is properly cited.

Denvil Duncan*, Arthur Lin Ku, Alyssa Julian, Sanya Carley, Saba Siddiki, Nikolaos Zirogiannis and John D. Graham

\title{
Most Consumers Don't Buy Hybrids: Is Rational Choice a Sufficient Explanation?
}

\begin{abstract}
Although federal regulation of vehicle fuel economy is often seen as environmental policy, over $70 \%$ of the estimated benefits of the 2017-2025 federal standards are savings in consumer expenditures on gasoline. Rational-choice economists question the counting of these benefits since studies show that the fuel efficiency of a car is reflected in its price at sale and resale. We contribute to this debate by exploring why most consumers in the United States do not purchase a proven fuel-saving innovation: the hybrid-electric vehicle (HEV). A database of 110 vehicle pairs is assembled where a consumer can choose a hybrid or gasoline version of virtually the same vehicle. Few choose the HEV. A total cost of ownership model is used to estimate payback periods for the price premiums associated with the HEV choice. In a majority of cases, a rational-choice explanation is sufficient to understand consumer disinterest in the HEV. However, in a significant minority of cases, a rational-choice explanation is not readily apparent, even when non-pecuniary attributes (e.g., performance and cargo space) are considered. Future research should examine, from a behavioral economics perspective, why consumers do not choose HEVs when pricing and payback periods appear to be favorable.
\end{abstract}

*Corresponding author: Denvil Duncan, School of Public and Environmental Affairs, Indiana University, SPEA 375F, 1315 East 10th Street, Bloomington, Indiana 47403, USA, e-mail: duncande@indiana.edu

Arthur Lin Ku: School of Public and Environmental Affairs, Indiana University, Bloomington, Indiana 47403, USA, e-mail: alku@iu.edu

Alyssa Julian: Vanderbilt University, Nashville, Tennessee, 37235 USA, e-mail: alyssa.a.julian@vanderbilt.edu

Sanya Carley: School of Public and Environmental Affairs, Indiana University, Bloomington, Indiana 47403, USA, e-mail: scarley @indiana.edu

Saba Siddiki: School of Public and International Affairs, Syracuse University, Syracuse New York, 13210 USA, e-mail: ssiddiki@maxwell.syr.edu

Nikolaos Zirogiannis: School of Public and Environmental Affairs, Indiana University, Bloomington, Indiana 47403, USA, e-mail: nzirogia@indiana.edu

John D. Graham: School of Public and Environmental Affairs, Indiana University, Bloomington, Indiana 47403, USA, e-mail: grahamjd@indiana.edu 
Keywords: cafe; fuel valuation; law and regulation; total cost of ownership; transportation.

JEL classifications: D61; G18; L91.

\section{Introduction}

The process of technological innovation is challenging, especially as innovators work to commercialize their discoveries. In the energy-efficiency arena, concerns have been raised that consumers are often slow to adopt new technologies, a reticence that hinders the commercialization process. If consumers are reluctant to purchase new technologies, producers will be reluctant to supply them. Without producers and consumers working in tandem, market forces will not commercialize technological innovations at a rapid rate.

Why are consumers reluctant to purchase fuel-saving technologies? Broadly speaking there are two possible answers. The first is that fuel-saving technologies may not pass the consumer's private benefit-cost test (Gayer \& Viscusi, 2013; Mannix \& Dudley, 2015). Such technologies are often more expensive to purchase than traditional technologies. It is possible that the consumer refuses to buy these products because she perceives that the fuel savings are not large enough - given the consumer's time preferences - to cover the additional costs within the expected life of the product. Alternatively stated, fuel-saving technology has a payback period that exceeds the product's useful life. Even if the new technology is not more expensive to purchase, it may have drawbacks (e.g., performance, quality, or convenience) that the consumer believes outweigh the private fuel-saving benefits (Small, 2010; Allcott \& Greenstone, 2012; Helfand et al., 2016).

The second is that consumers may impose "internalities" on themselves, perhaps by undervaluing fuel savings (Allcott et al., 2014). Behavioral economics suggests that undervaluation could arise for several reasons. Consumer investments in energy efficiency can be complex decisions where the consumer may be considering multiple factors with incomplete information. Energy efficiency may not be perceived as the most crucial consideration, possibly creating "inattention bias" (Lacetera et al., 2012; Sallee, 2014). ${ }^{1}$ Moreover, the size of the price premium for energy efficiency may be clear but the extent of the savings may be uncertain, which introduces the possibility of loss aversion or simply status quo bias

1 Acquiring information is costly and inconvenient, and available sources of information may have uneven reliability. It may be difficult for the consumer to figure out how much searching around is worthwhile. 
(Greene, 2011; Thaler \& Sunstein, 2008). When near term investments produce savings for the consumer, those savings may occur only after a considerable period of delay, which introduces the possibility of a "present bias" that is greater than justified by the real interest rates observed in the economy on a day-to-day basis (Hausman, 1979; Allcott, 2013). ${ }^{2}$ Although these perceptual biases have been framed from the consumer's perspective, they may also influence the viewpoints of producers, which can also help explain a slow rate of diffusion of new technologies (Blumstein \& Taylor, 2013; NRC, 2015a).

A situation where private opportunities for profitable energy-efficiency investments are feasible but consumers and producers do not make those investments is called the "energy-efficiency gap" (Jaffe \& Stavins, 1994; Gillingham \& Palmer, 2014). The resulting "investment inefficiencies" represent "a wedge between the cost-minimizing level of energy efficiency and the level actually achieved" (Allcott \& Greenstone, 2012, 4).

In this paper, we contribute to scholarship on the energy-efficiency gap by exploring why most U.S. consumers are not purchasing a proven fuel-saving innovation: the hybrid-electric vehicle (HEV). We undertook a detailed paired analysis of HEVs and gasoline-fuel comparators that were offered in the U.S. new vehicle market from 2006 to 2016. We identified $110 \mathrm{HEVs}$ and, for each HEV, we identified an internal combustion engine (ICE) vehicle that most closely resembles it. We collected data on suggested retail price, Environmental Protection Agency (EPA) rated fuel economy, cargo space, power, and other vehicle characteristics that people tend to consider when purchasing a car.

We use these data to estimate the payback period for each HEV in a total cost of ownership (TCO) model, which is intended to simulate a rational-choice perspective. ${ }^{3}$ In particular, we ask the following question: Suppose a consumer buys a HEV and holds it for its expected lifetime (approximately 16 years): How many years of accumulated fuel savings would it take to cover the incremental costs of purchasing and owning the HEV? ${ }^{4}$ We estimate this "payback period" using five distinct definitions of the price premium. The first two are the manufacturer's suggested

2 Consumers are known to shy away from making present-value calculations and multi-attribute optimizations; instead, they are presumed to engage in intuitive or satisficing behaviors that simplify complex problems and moderate the costs of decision making (Newell et al., 1958; Simon, 1976; Kahneman et al., 1982).

3 The payback period is calculated based on the present value of fuel savings. We fix the discount rate and vary the number of years over which the fuel savings are discounted in order to find the number of years it takes to recover the extra cost of HEVs. An alternate approach is to discount the fuel savings over the entire life of the vehicle and vary the discount rate so as to identify the discount rate at which the present value of fuels savings cover the extra cost of HEVs.

4 Incremental costs are defined to include the price premium, sales taxes, insurance and loan financing costs. 
retail price ("baseline" price) and the baseline adjusted for tax credits ("adjusted baseline"). Then, starting with the adjusted baseline, we use the hedonics literature to adjust for the monetary value of cargo space and power, separately and jointly.

The results show that the majority of HEVs have payback periods that extend well beyond the expected life of a new vehicle. Approximately $26.4 \%$ allow the consumer to recover the investment within 16 years in our baseline analysis. Adjustments for tax credits and cargo space increases the share of vehicles with payback periods less than 16 years to $32 \%$. Finally, we find that adjusting for vehicle power has a substantial negative effect on the payback periods; only $12 \%$ of the HEVs allow consumers to recover their investments within 16 years.

Our findings suggest that most HEV offerings do not pass a private benefitcost test and thus we cannot rule out the possibility that consumers act rationally in choosing not to buy HEVs. Still, there are approximately $12 \%-32 \%$ of HEVs that do not appear to fit this model, where the range depends on consumer valuation of power. A more in-depth analysis of these vehicles did not uncover any decisive information that can explain why consumers do not buy them. Specifically, we checked for differences in upgrade packages and drivability issues. We find that HEVs generally have more upgrades than their ICE comparators, which suggests that this cannot explain the poor sales data. We capture drivability issues by using new car reviews prepared by consumer-facing auto experts. While some reviewers point to drivability issues with some of the HEVs (e.g., subtle differences in braking and handling), those concerns were not replicated by all the reviewers and they were not sufficiently widespread to explain the low take-up among the HEVs with attractive payback periods. As a result, we recommend additional research to determine whether the low sales performance of these HEVs could be due to undervaluation of the private benefits of fuel-saving technology. We also connect our findings to the ongoing public debate about the future of Corporate Average Fuel Economy (CAFE) standards, since consumer undervaluation is considered a central rationale for the 2017-2025 standards that our now under "midterm" review (McConnell, 2013; Helfand \& Dorsey-Palmateer, 2015).

This research makes useful policy as well as academic contributions. First, we provide a detailed study of vehicle pairs that allows us to comment on the energyefficiency gap in a setting that is more applicable to the current policymaking environment than previous studies (Busse et al., 2013; Allcott, 2013; Allcott \& Wozny, 2014; Sallee et al., 2016). While these recent studies provide strong evidence on the subject matter, the fuel savings they study are based on variation in fuel prices. The fuel savings induced by CAFE are due to changes in technology rather than fuel price, and therefore it is possible that the response of consumers will be different, thereby limiting the extent to which the new literature can inform current debates about CAFE. Second, our results open up a new line of academic research that can explore why consumers, when offered an attractive HEV option, choose 
instead the traditional gasoline engine. We envision an array of stated-preference and revealed-preference studies, coupled with basic social science research and international comparisons, to shed further light on consumers' valuation of fuelsaving technology.

Admittedly, our findings are derived from analysis of only one technology, and thus questions about the generalizability to all fuel-saving technologies are warranted. However, it is not immediately clear that other fuel-saving technologies will perform better than HEVs. For example, plug-in electric vehicles (PEVs) have been demonstrated to have similar or better power than gasoline vehicles and greater fuel savings than HEVs (NRC, 2015b). However, PEVs have other drawbacks such as limited driving range, long recharging times, and complications with home, office, and public charging stations that are not a factor with HEVs. Nonetheless, we believe a similar paired-comparison study that focuses on PEVs might provide additional insights.

The remainder of the paper is organized as follows. Section 2 describes the consumer fuel valuation literature and how our paper fits within this literature. Section 3 justifies our focus on HEVs as a test case for our analysis. We describe the data and methods in Section 4, provide results and case studies of specific vehicles in Section 5, and conclude with policy implications and research recommendations in Section 6.

\section{The consumer valuation literature}

The literature on consumer valuation of fuel economy is limited but growing rapidly. The recent literature has two divergent strands: one is rooted in the troubled commercial experience of the auto industry with fuel-saving technologies and the related results of marketing and stated-preference surveys. The other is rooted in econometric analyses of vehicle transactions data where efforts are made to show how much of future fuel savings are capitalized in the prices of used or new vehicles.

The first strand suggests that consumers, when considering a fuel-efficient vehicle, value only a small fraction of the present value of the fuel savings accumulated over the lifetime of the vehicle. The second strand suggests that the prices paid for vehicles reflect most or all of the fuel savings expected over the life of the vehicle. For analysts in federal agencies performing benefit-cost analyses of CAFE standards, the findings from the two literatures are difficult to reconcile (for details, see the Technical Assessment Report (TAR) 2016). This is a vivid illustration of a more general dilemma agency analysts have in dealing with hypotheses and evidence from the field of behavioral economics (Robinson \& Hammitt, 2011). 
Specifically, on the first strand, a recent committee of the National Research Council of the National Academies of Sciences surveyed practitioners in the industry and concluded: "... auto manufacturers perceive that typical consumers would pay upfront for only one to four years of fuel savings, a fraction of the lifetime discounted present value" (NRC, 2015a). Supporting the industry's view is the fact that decades of effort to market fuel-saving technologies have not been very successful in the U.S. (e.g., the failed efforts of Chrysler and Honda to market fuel-economy innovations in the 1970s and 1990s, respectively) (German, 2015; Carley et al., 2017). Household surveys also show that motorists do not keep track of their gasoline expenditures, do not make present-value calculations about possible fuel savings, and do not make much use of expert services that could help them evaluate fuel-economy investments (Turrentine \& Kurani, 2007; Schewel \& Kammen, 2010). Large-sample surveys of new car buyers - both before and after they make their purchase - show that fuel economy is a salient consideration but it ranks behind other vehicle attributes such as reliability, durability, value for money, quality of workmanship, manufacturer's reputation, safety design features, ease of handling/maneuverability, warranty/guarantee, seating comfort, and engine performance (e.g., NRC, 2015a,b). There is a small subset of car buyers that rank fuel economy as the most important attribute, and similar respondents (e.g., those who seek to make an environmental statement with their choice) have often been early adopters of the Prius, but even respondents who say they care deeply about fuel economy do not necessarily purchase vehicles with high fuel economy (NRC, 2015a; Popiel, 2011; Rechtin, 2007). Stated-preference surveys find that consumers are willing to pay only a small fraction of the fuel savings that new technology will provide over the lifetime of a vehicle; typical respondents require a payback period of three years for such investments (Liu, 2014; Greene et al., 2013; Nixon $\&$ Saphores, 2011). This line of evidence tends to support federal agency practice of counting private fuel-saving benefits in societal benefit-cost analyses of CAFE standards.

A second strand of studies from the economics literature seeks to determine whether the prices of new and used cars reflect the capitalized value of enhanced vehicle fuel economy. The early generation of such studies - published roughly from 1980 to 2009 - provided mixed results but the research designs were often cross-sectional, without good instruments for identification of a fuel-economy effect on vehicle price (for reviews of this literature, see Greene, 2010; Helfand \& Wolverton, 2011; NRC, 2015a). The more recent generation of studies, which use fuel price changes to isolate the effect of vehicle fuel economy on vehicle price, is rigorous in design and provides more consistent results. Specifically, much or all of the present value of lifetime fuel savings of vehicles with higher fuel economy appear to be reflected in the prices of new and used vehicles, though the body of evidence is much larger on prices of used vehicles than new vehicles (e.g., see Busse 
et al., 2013; Gilmore \& Lave, 2013; Allcott \& Wozny, 2014; Grigolon et al., 2014; Sallee et al., 2016). If the inferences from this literature are accurate and applicable to regulated vehicles with new fuel-saving technology, then federal agency practice of counting private fuel savings in official benefit-cost analyses of CAFE standards is questionable (Gayer \& Viscusi, 2013).

While the second generation of studies provides rigorous econometric evidence on consumers' valuation of fuel savings, there is some concern that the findings have limited applicability to CAFE because their identification strategies rely on changes in fuel prices. Since the fuel savings induced by CAFE are due to changes in technology rather than fuel price, it is possible, from a behavioral perspective, that consumer responses will be different (Greene \& Welch, 2016). This follows not simply from cognitive considerations but from the fact that adopting a fuelsaving technology can change more than fuel costs. New technology often affects the vehicle's power, handling, cargo space, and physical appearance. Additionally, the ability of the technology to produce the advertised fuel savings may be questioned, a discrepancy that has occurred particularly with HEVs (Healey, 2014).

The fact that adopting a fuel-saving technology changes other attributes of a car means that it is very difficult to identify the energy gap based on changes in technology. Identifying the gap requires researchers to compare two cars that are identical in every way except for fuel efficiency. The research question is, then, what happens to the relative price of the two cars as fuel prices increase, with the expectation being that the price of the more efficient car will increase by $\$ 1$ for every $\$ 1$ reduction in its present-value fuel costs relative to the fuel cost of the inefficient car. This is relatively difficult to do when fuel costs are driven by changes in technology rather than fuel price; and it partly explains why the literature has focused on variation in fuel price as the primary identification strategy. The pairedcomparison approach employed in this analysis reduces the difficulty by focusing on one type of fuel-saving technology for which it is possible to find a suitable comparator among ICE vehicles. Our approach is complementary to a very recent paper by Leard et al. (2017), who find consumer undervaluation of fuel economy but also consumer valuation of power.

Consumer information programs might shed light on this debate but evidence on the role of consumer information in changing consumer decisions about fuel economy is mixed (Camilleri \& Larrick, 2014; Saulsbury et al., 2015). There is clear evidence that consumers misinterpret the miles-per-gallon metric and it is plausible that gallons per mile might be more intuitive (Larrick \& Soll, 2008). Some consumers are concerned that their personal fuel-economy experiences with specific models do not align with the ratings on official EPA fuel-economy labels (Schewel \& Kammen, 2010; Nelson, 2013; NRC, 2015a). EPA and automakers have taken steps to make the labeling information more realistic, especially for 
HEVs, and to provide more prominent information on fuel savings that will be experienced over a five-year period of ownership (EPA, 2011).

The only randomized test of the new EPA labels found no evidence that they change the stated intent of new car buyers to purchase an HEV, plug-in hybrid, or plug-in electric vehicle (Dumortier et al., 2015). There is some experimental evidence that information on total cost of ownership might change the stated purchasing intentions of car buyers but the same experiment found no evidence that such information would change the stated purchasing intentions of SUV buyers (Dumortier et al., 2015). Two recent experiments - one in-person at Ford dealerships and the other online - provided car shoppers with individually tailored information on fuel economy and fuel expenditures (annual and vehicle lifetime) for several vehicles that were under serious consideration. The experiments found no evidence that the information altered the actual purchasing decisions of consumers (Allcott \& Knittel, 2017). As we discuss in the conclusion, a variety of informational experiments that focus on the HEV option may be a fruitful path forward, given our findings and this previous literature.

\section{$3 \mathrm{HEVs}$ as a test case of consumer valuation of fuel economy}

In this article, we explore what can be learned about consumer valuation of fuel economy from the proliferation of HEVs that have been marketed to consumers since the Honda Insight and Toyota Prius entered the U.S. market in 1999-2000 (McConnell \& Turrentine, 2010). This section describes HEVs and highlights some of the features that make them appealing for our analysis.

\subsection{HEV vs. traditional internal combustion engine}

HEVs are a suitable technology to assess for our purposes because the HEV does not require any behavioral change by the motorist in the refueling process, nor does the HEV require purchase, permitting, or installation of recharging equipment. Thus, it is a more straightforward case of consumer investment in fuel economy than plug-in electric vehicles. Additionally, in most cases the HEV is visually 
indistinguishable from its gasoline counterpart, so there are no subjective issues about vehicle appearance or styling that complicate consumer choice.

\subsection{Evolution of HEV technology}

The early versions of HEVs had some drawbacks related to performance, cargo space, and drivability but creative engineering has, over time, minimized such concerns while retaining (or even increasing) the fuel economy of the HEV (NRC, 2015a). For example, the Insight and Prius were designed with an input power-split system that uses two large electric motors and a planetary gear system in place of a conventional transmission. More recently, several other manufacturers have introduced alternative designs of the HEV that compensate for some of the drawbacks of the power-split system (e.g., the P2 hybrid) (NRC, 2015a). The chemistry of the batteries used in HEVs were originally nickel metal hydride (NiMH) but some HEV models are now making use of lithium ion (Li-ion) (Greimel, 2015). Overtime, HEV technology has become progressively less expensive without losing gains in fuel economy (NRC, 2015a).

\subsection{Fuel savings}

For the everyday driver, the HEV may feel similar or subtly different from a gasoline-powered vehicle, but the refueling experience is the same, except that it occurs less frequently with an HEV than a comparable gasoline engine. HEVs can be purchased for a price premium but the consumer will experience gasoline savings over the life of the vehicle. The magnitude of the HEV's fuel-economy advantage varies across models but can be as much as a $30 \%$ gain over an otherwise similar gasoline-powered vehicle (German, 2015; NRC, 2015a). The fueleconomy advantage tends to be greatest in low-speed city driving, where electrical power alone can do the job. At high speeds, HEVs may rely entirely on the gasoline engine or a combination of electrical and gasoline energy.

HEVs save gasoline for multiple reasons: they capture and reuse energy lost during braking (regenerative braking), can maintain performance with a smaller, more efficient gasoline engine, can shut the engine off at idle and at very low load conditions when the engine is very inefficient, and can optimize use of the gasoline engine at appropriate speeds since electric power is also available. HEVs also provide accessory power more efficiently than the alternator in a gasoline-powered vehicle. We do not address in this article mild hybrids and microhybrids since they 
have insufficient real-world marketing experience, though they may prove to be more cost effective than full HEVs in the next decade (German, 2015). On the other hand, gasoline-powered vehicles are also becoming more fuel efficient (e.g., due to use of smaller, turbocharged gasoline engines), so the HEV faces a more fuel-efficient competitor today than it did a decade ago (Carley et al., 2017).

\subsection{Production and repair costs}

HEVs are inherently more expensive to produce because they have two propulsion systems rather than one. The size of the HEV cost disadvantage has been declining steadily for the last decade due to innovation in production processes and economies of scale (German, 2015; NRC, 2015a). If manufacturers chose to price an $\mathrm{HEV}$ at mass-production, marginal cost, the incremental price today would be in the range of $\$ 4000$ to $\$ 5700$, depending on the application (e.g., subcompact car versus large SUV) (NRC, 2015a; TAR, 2016). For low-volume HEV offerings, it is not uncommon to observe price premiums between $\$ 5000$ and $\$ 10,000$ (Popiel, 2011). The average price of an HEV is about $\$ 5000$ higher than similar gasolinepowered vehicles, while average fuel economy is about 6 miles per gallon larger, but the variations around the averages are quite large (Liu, 2014). As we shall see, there are cases where the manufacturer prices an HEV well below the company's marginal cost, thereby providing - as we discovered - valuable information on consumer valuation.

With its two propulsion systems, one might surmise that the HEV repair and maintenance expenses would be elevated. Some media reports have speculated that, after 80,000 miles or so, the batteries in the hybrid system experience a gradual loss of capacity and performance (Duffer, 2014). However, the experience of HEV taxi fleets, where average vehicle mileage exceeds 300,000 miles, suggests that the hybrid powertrain components outlast the life of the vehicle (Truett, 2016). Indeed, manufacturers typically offer longer warranties on hybrid components than on gasoline-engine components (Edmunds.com, 2017). On the other hand, HEVs require fewer oil changes and brake repairs than gasoline vehicles, and those expenses are typically a significant share of a vehicle's total annual maintenance and repair costs (Dublin, 2012). Lacking definitive data on this subject, we use the simplifying assumption that the two propulsion systems have similar maintenance and repair costs (for a more detailed discussion aimed at consumers, see Brinson, 2018). 


\subsection{HEV sales}

The Honda Insight was the first HEV offered in the U.S. (1999) and showcased Honda's green technology (i.e., aluminum body and unprecedented aerodynamics as well as a hybrid propulsion system). However, few US consumers were interested in a tiny two seater. The offering was terminated in the US after several years but sold much better in Japan.

The commercial success of the midsized Toyota Prius is well known, with national sales reaching an annual peak of 236,659 in 2012; indeed, the Prius was the \#1 selling passenger vehicle in California in both 2012 and 2013. The Prius received a boost from early-adopter enthusiasm, favorable federal and state tax treatment, and access to the coveted HOV lanes in California and other congested states (Undercoffler, 2015; Ohnsman, 2014; Hirsch, 2015). At one point a used Prius with an HOV-lane sticker in California was sold at an average price $\$ 4000$ higher than a used Prius without the HOV-lane sticker (NPR, 2007; Shewmake \& Jarvis, 2014). Prius sales have declined steadily since 2012 for a variety of reasons: HEVs are no longer permitted on HOV lanes; federal and state tax incentives for HEVs have been reduced or eliminated; fuel prices have declined substantially; green activists and social marketers are promoting plug-in electric vehicles instead of HEVs; and the conventional gasoline engine is becoming more fuel efficient (Cobb, 2017; Carley et al., 2017). Although our study cannot include the Prius, the presence of the Prius in the marketplace may have depressed the uptake of other midsized HEV models, since early adopters were attracted to the Prius.

Most consumers in the US do not purchase hybrids. As a share of the new U.S. passenger vehicle market, HEVs hit a peak of 3.6\% in 2012-2013 but that share was less than 3\% in 2016 and 2017 (McVeigh, 2016; Wards Automotive, 2018). The take-up rates for hybrids (when vehicle manufacturers offer both a gasoline and hybrid version of the same model) range from less than $1 \%$ to a maximum of $24 \%$. In the vast majority of cases the take-up rate is less than $10 \% .{ }^{5}$ The question we seek to answer is whether rational-choice modeling would predict low take-up rate.

\subsection{Predictions}

Based on rational-choice theory, we predict that an HEV will be purchased if the present value of fuel savings are greater than the price premium of the HEV (tak-

5 The data are collected and compiled from online sources. The hybrid sales data come from hybridcars.com and, for general model sales, goodcarbadcar.net. 
ing into account any applicable tax effects or other financial factors). Where feasible, we also apply shadow prices to nonfinancial vehicle characteristics that differ between the HEV and its gasoline comparator. If an HEV is economically attractive but not purchased, we look for hidden amenity costs or other drawbacks that might explain the consumer disinterest (Small, 2010; Allcott \& Greenstone, 2012). Where no such drawbacks exist or appear to be significant, we hypothesize that behavioral (non-rational) explanations play a role such as undervaluation of fuel savings.

\section{Data and methods}

This section describes the data and empirical analysis we employed to evaluate HEV offerings and their gasoline-powered comparators.

\subsection{Data}

We collected data on 110 pairs of vehicles from various sources, where each pair includes one HEV and one gasoline comparator. The comparator is chosen to be as similar as possible to its matching HEV. Our data includes virtually every HEV offered from 2006 to 2016 except for the "dedicated" hybrids (e.g., the Prius) that have no gasoline version.

The first layer of comparison is physical appearance; we select gasoline vehicles that are difficult to distinguish from their respective HEVs based solely on looks. Where an HEV has multiple physically similar gasoline comparators, we then select the trim of the gasoline vehicle that is most similar to the HEV, considering curb weight, number of cylinders, and drivetrain. In most cases the matching is straightforward because manufacturers generally produce both an HEV and gasoline version of the same model and trim. For example, there is a hybrid and gasoline version of the 2017 Honda Accord LX. There are some cases, especially for the pre2010 models, where there is no gasoline version of the same trim. In these cases we select the gasoline trim that is most similar to the HEV. For example, the 2007 Honda Accord hybrid is matched with the Honda Accord EX-L. ${ }^{6}$

Our analysis does not include the Toyota Prius because it is a dedicated hybrid ${ }^{7}$ and many of its owners are "early adopters", which means they sought techno-

\footnotetext{
6 The list of vehicle pairs is provided in Table A1 of Appendix 1.

7 As a dedicated hybrid, the Prius has no gasoline counterpart. Comparisons of the Prius to the Corolla and Corona are possible and sometimes made but are arguable with respect to comparability (see, for example, the Prius-Corolla comparison by DeMuro, 2013).
} 
logical or environmental status with their purchase (Heffner et al., 2007; NRC, 2015a,b; Delgado et al., 2015; Sexton \& Sexton, 2014; Ozaki \& Sevastyanova, 2011; McCormick, 2015; Rechtin, 2007; Kahn, 2007). Our focus is not early adopters but the mainstream retail purchaser of vehicles who could buy an HEV version of their chosen manufacturer/brand/model/trim.

After selecting the vehicle pairs, we then collect detailed information on each vehicle. The list of variables can be classified into three groups. First, we collect data on combined miles per gallon (MPG) and manufacturer suggested retail price (MSRP). Use of MSRP data will understate the average transaction price for HEVs when fuel prices are high and overstate them when fuel prices are low, since dealers vary the relative size of the price discount for HEVs depending on the fuel price environment (Mullaney, 2015; Consumer's Union, 2015). These MPG and price data are supplemented with data on sales tax rates, federal tax credits, insurance premiums, loan costs, vehicle miles travel, vehicle survival (scrappage) rates, and fuel price at time of purchase. These data are used to estimate payback periods using a total cost of ownership framework. Second, we collect data on cargo space, horsepower, 0-60 miles per hour time, torque, and curb weight. We use these data to incorporate shadow prices for cargo space and power.

Finally, we collect data on standard vehicle features such as entertainment and safety packages that may differ between HEVs and gasoline vehicles. We use these variables to provide a qualitative assessment of the likelihood that the observed pattern of sales is consistent with a rational model of consumer behavior. For example, a consumer may decide not to purchase an HEV with an attractive payback period because she values the upgrade packages that come standard only with a gasoline comparator. Unfortunately, we are limited to a qualitative assessment because we are not able to calculate shadow prices for the upgrade features.

Our data cover 22 brands and 54 unique models for model years 2006 to 2017. The model-year coverage varies across HEVs; while some HEVs were introduced only recently, others have been offered for a decade or more and therefore have multiple generations. We collect data for the first model year of each generation of HEV. For example, our data include the 2007 and 2012 Ford Escape Hybrid and the 2010 and 2016 Ford Fusion Hybrid. Therefore, the number of observations for each HEV depends on the number of generations of that HEV produced from 2007 to 2017. See Table A1 in the Appendix for the full list of vehicle pairs used in our analysis.

Table 1 summarizes the values for some of our key variables by time period; panels $\mathrm{A}$ and $\mathrm{B}$ report the means for HEV and ICE, respectively, while panel $\mathrm{C}$ reports the mean of the differences between HEVs and ICEs. Looking at the full sample period, we find that the average HEV consumed one fewer gallon of gaso- 
Table 1 Summary statistics.

\begin{tabular}{|c|c|c|c|c|c|}
\hline & 2006-2008 & 2009-2011 & 2012-2014 & 2015-2017 & Total \\
\hline Details & \multicolumn{5}{|c|}{ Panel A: Gasoline vehicle (ICE) } \\
\hline \multirow[t]{2}{*}{ Gallons per 100 miles } & 5.01 & 5.78 & 4.74 & 4.00 & 4.63 \\
\hline & $(0.83)$ & $(1.15)$ & $(1.01)$ & $(0.51)$ & $(1.05)$ \\
\hline \multirow[t]{2}{*}{ Horse power } & 217.89 & 310.10 & 249.90 & 227.29 & 244.84 \\
\hline & $(67.81)$ & $(95.53)$ & (70.87) & $(55.65)$ & $(75.52)$ \\
\hline \multirow[t]{2}{*}{ Cargo space } & 22.78 & 20.24 & 28.12 & 21.58 & 22.62 \\
\hline & $(15.47)$ & $(6.58)$ & (23.34) & $(14.41)$ & $(15.46)$ \\
\hline \multirow[t]{3}{*}{ Suggested retail price } & 32039.74 & 52733.91 & 36762.27 & 35520.12 & 38274.59 \\
\hline & $(7152.87)$ & $(25084.09)$ & $(15283.22)$ & $(12229.10)$ & $(16629.86)$ \\
\hline & \multicolumn{5}{|c|}{ Panel B: Hybrid-electric vehicle (HEV) } \\
\hline \multirow[t]{2}{*}{ Gallons per 100 miles } & 3.78 & 4.35 & 3.70 & 2.94 & 3.48 \\
\hline & $(0.70)$ & $(0.95)$ & $(0.71)$ & $(0.62)$ & $(0.90)$ \\
\hline \multirow[t]{2}{*}{ Horse power } & 203.63 & 300.35 & 234.85 & 209.53 & 229.63 \\
\hline & $(79.53)$ & $(100.00)$ & (78.26) & $(55.02)$ & $(80.46)$ \\
\hline \multirow[t]{2}{*}{ Cargo space } & 17.31 & 19.09 & 26.63 & 18.96 & 19.88 \\
\hline & $(7.70)$ & $(6.71)$ & $(23.83)$ & $(14.54)$ & $(14.67)$ \\
\hline \multirow[t]{3}{*}{ Suggested retail price } & 39497.62 & 62338.43 & 42248.12 & 40276.10 & 44511.52 \\
\hline & $(10737.58)$ & $(28207.13)$ & $(15787.71)$ & $(16024.33)$ & $(19773.54)$ \\
\hline & \multicolumn{5}{|c|}{ Panel C: Difference between HEV and ICE } \\
\hline \multirow[t]{2}{*}{ Gallons per 100 miles } & -1.23 & -1.44 & -1.04 & -1.06 & -1.15 \\
\hline & $(0.29)$ & $(0.51)$ & $(0.41)$ & $(0.41)$ & $(0.43)$ \\
\hline \multirow[t]{2}{*}{ Horse power } & -14.26 & -9.75 & -15.05 & -17.76 & -15.21 \\
\hline & (22.56) & (43.53) & $(28.95)$ & $(43.85)$ & $(38.09)$ \\
\hline \multirow[t]{2}{*}{ Cargo space } & -5.47 & -1.16 & -1.49 & -2.62 & -2.74 \\
\hline & (13.41) & (2.93) & $(1.80)$ & $(1.78)$ & (6.12) \\
\hline \multirow[t]{2}{*}{ Suggested retail price } & 7457.89 & 9604.53 & 5485.85 & 4755.98 & 6236.93 \\
\hline & (3902.41) & $(6282.19)$ & $(2768.21)$ & $(5653.47)$ & $(5372.31)$ \\
\hline N. Obs. & 19.00 & 20.00 & 20.00 & 51.00 & 110.00 \\
\hline
\end{tabular}

Notes: Panels A and B report the mean and standard deviation of each variable; standard deviations are in parentheses. For each variable, Panel $\mathrm{C}$ reports the mean and standard deviation of the difference between HEVs and ICEs (standard deviations are in parentheses) so negative numbers indicate that ICEs have a larger value compared to HEVs. Number of observation for cargo space is 16 in the 2009-2011 and 2012-2014 time periods.

line per 100 miles but cost $\$ 6236$ more than the average ICE. As expected, HEVs tend to be less powerful (as measured by horsepower) and have less cargo space. 
Interestingly, Table 1 shows that, while HEVs and ICEs have become more fuel efficient over time, the average fuel efficiency advantage of HEVs has remained almost constant. ${ }^{8}$ Concurrently, HEVs have become relatively cheaper over time; the average premium falls from a peak of $\$ 9604$ for the 2009/2011 models to $\$ 4755$ for the 2015/2017 models (MSRPs). The difference in horsepower has increased slightly while HEVs have made significant gains in cargo space. Finally, we find that average fuel prices (real 2015 dollars) rose over the first three periods, peaking at $\$ 3.63$ per gallon in $2012 / 2014$ before falling to $\$ 2.37$ per gallon in $2015 / 2017$.

\subsection{Methodology}

The data described above are used to calculate the payback period for each hybrid relative to its gasoline comparator. This means that we implicitly are focusing on consumers who can decide between the HEV and the gasoline comparator that we have paired with the hybrid. The calculations are done using the Total Cost of Ownership (TCO) framework, which is an established rational-choice framework that is often used in the auto sector to compare different products (e.g., see Al-Alawi \& Bradley, 2013). Key variables include the HEV gross price premium, any applicable federal tax credit for the HEV, the difference in vehicle fuel economy, vehicle miles of travel by vehicle age, the vehicle scrappage rate by vehicle age, the average interest rate on new auto loans in the year of purchase, and the average national fuel price at the time of purchase. We also incorporate shadow prices for vehicle power and cargo space and include these in the TCO. Below we describe how we operationalize each of these components. Appendix 2 provides technical details about how the TCO model is structured.

\subsubsection{Baseline}

Our baseline model estimates payback period in three steps. First, we estimate the adjusted gross price premium, $\mathrm{Pa}$, as the sum of gross price premium, auto insurance costs, loan financing costs, and sales taxes. Gross price premium refers to the difference between the MSRP for a hybrid and its gasoline comparator. Ideally, we would want to use the average actual sales price for each vehicle. However, we rely

\footnotetext{
8 We acknowledge that these trends reflect composition effects (number and type of HEV varies across the sample period) and changes in technology costs. Notice that the number of HEVs in our sample increases from 19 in the first period to 51 in the last period. The total number of HEVs offered in 2016 was 55, which includes the Prius and a few other excluded vehicles.
} 
on the MSRPs since we do not have access to the actual transaction prices. Our data on auto insurance costs reflect general trends in the insurance industry and are not specific to the vehicles in our analysis. Loan financing costs are based on yearspecific 60-month auto loan rates and are taken from the St. Louis Federal Reserve, again not specific to our vehicle pairs (Board of Governors, 2017). Sales tax reflects the population-weighted average retail sales tax rate in the US.

Second, we estimate the present value of fuel savings at each age, $t \in(1,30)$, in a vehicle's life, where each age refers to year 1 to year 30 of a vehicle's lifetime. We then use combined miles per gallon (MPG) published by the EPA, fuel price, vehicle miles traveled (VMT), and survival rates as follows:

$$
F_{h t}=\left(\frac{1}{f_{i}}-\frac{1}{f_{h}}\right) * \mathrm{VMT}_{t} * \text { survival rate } t * \text { fuel price } * d^{t},
$$

where $f_{h}$ and $f_{i}$ refer to combined mpg for hybrids and gasoline vehicles, respectively, and $d(=1 /(1+r))$ is the discount factor on future financial impacts. We assume that fuel economy labels produced by the EPA reflect the on-road MPG of each vehicle. HEVs initially overperformed on laboratory tests. However, the EPA updated its methodology in 2008 and again 2017 to address these concerns. ${ }^{9}$ If HEVs continue to overperform in laboratory testing, then this would imply that our results are conservative. In other words, the payback on HEVs would be higher than we report in our results. VMT and survival rates are taken from the agencies' midterm report on the CAFE standards, and reflect the National Highway Traffic Safety Administration's (NHTSA) most recent estimates for mileage and survival by vehicle age (TAR, 2016); see Figure 1. Fuel price is taken from the Energy Information Administration (EIA) and reflects the fuel price in the respective model years. ${ }^{10}$ In other words, we assume that consumers, at the time of purchase, use a flat fuel price forecast when considering future fuel expenditures (Anderson et al., 2013, 2011). All future dollar amounts are discounted to present value at the same rate as the 60-month loan rate for that model year and are reported in real 2015 dollars.

Finally, we estimate payback period as the number of years of accumulated fuel savings it takes to surpass the adjusted price premium, $P_{a}$.

$$
\text { Payback }_{h}^{\text {baseline }} \text { is } t \text { such that : } P_{a}-\sum_{1}^{t} F_{h t}=0 \text {. }
$$

\footnotetext{
9 See discussion on EPA website here: https://www.fueleconomy.gov/feg/ratings.shtml. 10 We assume throughout that model year corresponds to calendar year. We recognize that manufacturers generally begin producing and selling MY T in calendar year T-1.
} 


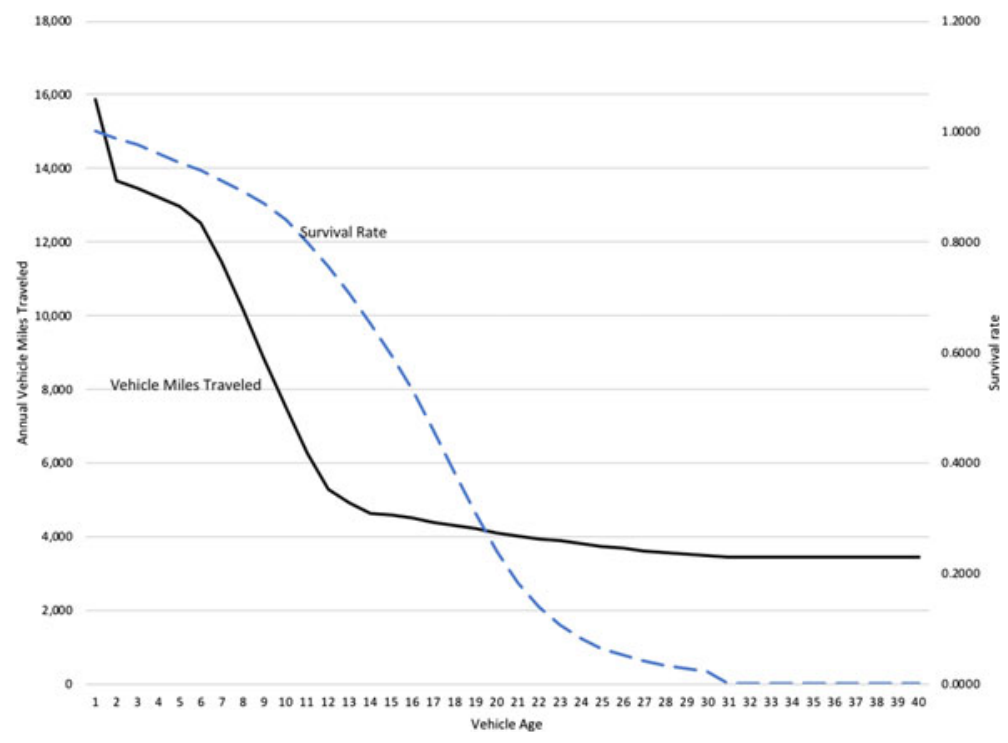

Figure 1 Vehicle miles traveled and survival rate by vehicle.

Source: National Highway Traffic Safety Administrations (NHTSA) most recent estimates for mileage and survival by vehicle age (TAR 2016).

Our analysis does not account for resale value. Even though consumers typically hold a new vehicle for less than half of its expected life, some recent econometric analyses, reviewed above, suggest that fuel-saving technology provides a price increment at resale that is roughly equivalent to the present value of fuel savings over the remaining vehicle lifetime. While we assume the consumer buys a vehicle and holds on to it, the addition of a resale step would not change our results, as long as the rational-choice assumption is maintained. Therefore, our analysis answers the question; how long does it take before the accumulated fuel savings cover the price premium of a HEV?

\subsubsection{Tax credits}

Cash incentives have been shown to spur sales of HEVs (Diamond, 2009; Chandra et al., 2010; Beresteanu \& Li, 2011; Gallagher \& Muehlegger, 2011; Jenn et al., 2013). The Energy Policy Act of 2005 authorized federal income tax credits for purchasers of HEVs that vary according to the rated fuel economy of the vehicle (KRT, 2005). The maximum credit was $\$ 3400$ per vehicle. The credits were 
gradually phased out when a manufacturer hit a HEV-sales threshold of 60,000 units. Toyota hit the threshold in mid-2006, and their HEV credit expired in September 2007; Honda's credit expired in December 2008; and Ford's credit expired in the spring of 2010 (Internal Revenue Service, 2009). The national program, which is estimated to have cost $\$ 1.4$ billion in foregone revenue, was terminated at the end of December 2010. Many states also offered (or still offer) incentives to purchase HEVs but the state incentives tend to be small compared to the federal credit, except for unusually large incentives offered temporarily by Colorado and West Virginia and the sales tax exemptions provided to HEV buyers in some states (Sallee, 2011; Diamond, 2009; Gallagher \& Muehlegger, 2011). Incentives less than $\$ 1000$ per vehicle do not have a detectable effect on HEV sales (Jenn et al., 2013; Diamond, 2009). We do not address the question of who ultimately benefits from purchase incentives: the producer or the consumer (see Busse et al., 2006; Sallee, 2011; Gulati et al., 2017).

In this analysis, we account for the federal HEV incentives only, which affect only some HEV models introduced before 2011. The number of HEVs offered in the US has mushroomed from 2 in 2000 to 24 in 2009 to 55 in 2016. The applicable federal credit is subtracted from the adjusted price premium before the consumer payback period is computed. In other words, we adjust the baseline by subtracting the tax credit from the numerator in Equation (2) where appropriate.

$$
\text { Payback credit is } t \text { such that: } P_{a}-\text { credit }-\sum_{1}^{t} F_{h t}=0 .
$$

\subsubsection{Shadow price for cargo and power}

HEVs and their gasoline-powered cousins are usually indistinguishable to the untrained eye (except when "Hybrid" is included on the name plate), but there are some subtle nonfinancial differences that might influence consumer behavior. For example, the hybrid version may have reduced cargo space (to make room for the large and heavy battery pack) or may have different performance characteristics (e.g., a typical pattern is somewhat faster performance from 0 to 30 miles per hour but slower performance from 0 to 60 miles per hour) (NRC, 2015a). Also, at any given trim level, the standard hybrid offering usually has more upgrade features than the corresponding gasoline model (rarely does the hybrid version have fewer upgrades). To account for nonfinancial features, we use literature values for the shadow prices for those nonfinancial factors (i.e., hedonic prices for cargo space and acceleration times). For a review of this literature, see Helfand et al. (2016). We found that the studies reviewed vary widely in technical quality and relevance. 
Table 2 Mean shadow price for power and cargo within a given time period.

\begin{tabular}{lrrr}
\hline Time period & Power & Cargo & Total \\
\hline $2006-2008$ & 288.79 & 264.80 & 551.28 \\
$2009-2011$ & 1436.86 & 51.61 & 1761.19 \\
$2002-2014$ & 1288.74 & 68.08 & 1512.44 \\
$2015-2017$ & 290.34 & 105.40 & 395.02 \\
\hline
\end{tabular}

Notes: Reported is the mean shadow price adjustment for power and cargo positive numbers indicate that the average HEV in the respective time periods has more power and cargo space than the average internal combustion engine vehicle.

To illustrate the potential importance of the nonfinancial features, we report consumer payback periods with and without the inclusion of shadow prices for cargo space and power using estimates from Delgado et al. (2015). ${ }^{11}$ That study has a research design and focus on HEVs that seems particularly appropriate for consumers who might consider purchasing a HEV. We then use the estimated shadow prices to adjust the price premium for cargo and power separately and jointly: ${ }^{12}$

$$
\begin{aligned}
& \text { Payback }_{h}^{\text {cargo }} \text { is } t \text { such that: } P_{a}-\text { credit }+ \text { cargo }-\sum_{1}^{t} F_{h t}=0 \\
& \text { Payback }_{h}^{\text {power }} \text { is } t \text { such that: } P_{a}-\text { credit }+ \text { power }-\sum_{1}^{t} F_{h t}=0 \\
& \text { Payback }_{h}^{\text {cargo \& power }} \text { is } t \text { such that: } P_{a}-\text { credit }+ \text { cargo }+ \text { power }-\sum_{1}^{t} F_{h t}=0 .
\end{aligned}
$$

\subsubsection{Other factors}

Hybrids rely on a relatively new technology in vehicles and this might raise concerns about the reliability of the vehicle and the realization of fuel savings. Concurrently, consumers who are uncertain about future fuel prices might view HEVs as

11 For our purposes, we requested that Delgado et al. supply us estimates of the shadow price of power where power was defined as horsepower per pound of vehicle weight. Those estimates, which are available upon request from the authors of this paper, were used in our calculations. We use these estimated coefficients to adjust each HEVs price for cargo and power. The price adjustments for power and cargo are summarized in Table 2.

12 Unfortunately, we are not able to monetize upgrade packages. Therefore, we present only a qualitative analysis of these features. 
a reasonable hedge against spikes in fuel prices. The TCO model does not account for these sources of valuation. It is difficult to predict the impact of these omissions on our results since serving as a hedge against spikes in oil prices reduces the payback period, while uncertainty about reliability increases payback period. We also do not account for maintenance costs.

\section{Results}

The financial case for purchasing each HEV is evaluated using a TCO model. The key summary statistic for each HEV model is the consumer's payback period - the average number of years of ownership and use that are required for the consumer to recoup the price premium paid for the hybrid. If the payback period is longer than the average life of a new vehicle observed in the market (about 16 years), then we presume that a consumer's decision not to purchase the HEV is rational. ${ }^{13}$ This section describes our findings. We begin with the baseline payback period. We then show how the results change as we account for tax credits, cargo space, and power.

We identify four payback thresholds that may be of interest. The first is three years, which some analysts take to be the maximum number of years that the average consumer is willing to wait to recoup the incremental costs of a fuel-saving technology (Small, 2010; Greene et al., 2013; Center for Automotive Research, 2011; NRC, 2015a). The second is based on the standard life of an auto loan ( six years), which is slightly shorter than the average ownership period for the original purchaser. The third is based on the expected life of a new car ( $\sim 16$ years $)$, and the last is based on the maximum age in the vehicle survival rate schedule (30 years). We believe the 16-year threshold is of strongest interest from a rational-choice perspective.

\subsection{Baseline}

Table 3 reports the percent of HEVs that have a payback period within the specified age thresholds for each of the price premium adjustments described in Section 4.2. Using the baseline price premium, we find that $26.4 \%(=29 / 110)$ of the HEVs paid for themselves within 16 years. This number falls to $9.1 \%$ when we limit payback to the general life of an auto loan, and $4.6 \%$ when we limit payback to

13 We estimated the expected life of a new car based on the survival rate schedule published in the Midterm review of the CAFE program (TAR, 2016). 
Table 3 Percent of cars that payback within a given time period.

\begin{tabular}{lcccr}
\hline & \multicolumn{4}{c}{ Annual VMT () } \\
\cline { 2 - 5 } Description & $\mathbf{1 - 3}$ & $\mathbf{1 - 6}$ & $\mathbf{1 - 1 6}$ & $\mathbf{1 - 3 0}$ \\
\hline Base & 4.55 & 9.09 & 26.36 & 27.27 \\
Base + credit & 4.55 & 12.73 & 31.82 & 32.73 \\
Base + credit + cargo & 4.55 & 12.73 & 31.82 & 32.73 \\
Base + credit + power $\left(^{*}\right)$ & 0.91 & 3.64 & 11.82 & 12.73 \\
Base + credit + power $\left({ }^{* *}\right)$ & 1.82 & 10.91 & 29.09 & 30.00 \\
\hline
\end{tabular}

Notes: Reported is the percent of hybrid-electric vehicles that have payback periods (in years) indicated by column titles. Each row represents a different measure of the adjusted gross price premium. Base indicates that adjustment is made for sales taxes, loan financing costs, and insurance costs. Credit indicates adjustment for tax credits, and Cargo and Power indicate adjustments for the shadow price of cargo space and power, respectively. VMT is vehicle miles traveled and is based on VMT schedule published by the National Highway Traffic Safety Administration in TAR (2016). ${ }^{*}$ The shadow price of power indicated is calculated based on estimates from Delgado et al. (2015). ${ }^{* *}$ The shadow price of power indicated is calculated based on estimates from Leard et al. (2017).

the 3-year period commonly believed to be the required payback period among typical vehicle owners. Importantly, $74 \%$ of the HEVs we examine do not pay for themselves within the expected life of a vehicle.

\subsection{Tax credits}

Results presented in the second row of Table 3 show that financial incentives offered by the government affect the number of vehicles with payback thresholds in the $1-16$ year range but not the 1-3 year range. In particular, $13 \%$ of vehicles payback within 6 years and $31.8 \%$ payback with 16 years when we account for tax credits. This result is largely a function of which cars are eligible for federal tax credits and the value of those tax credits. Table 4 shows the number of cars in each payback range that was eligible for a tax credit and the average credit amount. A total of 3 vehicles with payback periods less than 30 years qualified for the tax credits, but these cars had payback periods of 7-17 years. ${ }^{14}$ The average amount of the credit is $\$ 3000$ among the three cars.

14 An additional 18 vehicles qualified for tax credits, but these vehicles had payback periods of more than 30 years in the baseline. 
Table 4 Baseline payback periods and tax credits.

\begin{tabular}{lcrrr}
\hline & \multicolumn{4}{c}{ Years } \\
\cline { 2 - 5 } Description & $\mathbf{1 - 3}$ & $\mathbf{1 - 6}$ & $\mathbf{1 - 1 6}$ & $\mathbf{1 - 3 0}$ \\
\hline Base (\%) & 4.55 & 9.09 & 26.36 & 27.27 \\
\# of cars getting tax credit & & & 2 & 1 \\
Avg. amount of tax credit (\$) & & 3400 & 2200 \\
\hline
\end{tabular}

Notes: Reported is the percent of hybrid-electric vehicles (HEVs) that have payback periods (in years) indicated by column titles. Also included is the number of HEVs that receive tax credit and average amount of the credit. Base indicates that adjustment is made for sales taxes, loan financing costs, and insurance costs.

\subsection{Cargo space and power}

Cargo. Adjusting for differences in cargo space does not have any material effect on payback periods. Although payback periods change slightly for some vehicles, these changes are not large enough to affect the baseline results. This result is not surprising given that the average difference in cargo space between HEVs and their gasoline comparators is only 2.7 cubic feet. In other words, while consumers are willing to pay a significant price premium for additional cargo space, HEVs do not usually have a significant disadvantage on this dimension.

Power. The existing literature provides various measures of consumers' valuation of power. We rely on estimates from Delgado et al. (2015) and Leard et al. (2017) and find that estimated payback periods are somewhat sensitive to the valuation of power. Payback periods increase dramatically when we control for vehicle power using the estimates from Delgado et al. (2015). In particular, only $12 \%$ of vehicles payback within 16 years, 3.6\% payback within 6 years and $1 \%$ payback within 3 years after controlling for the shadow price of vehicle power. This reflects a combination of lower power among HEVs and a strong demand for power among consumers. Payback periods changed when we used the Leard et al. (2017) estimates, but the effect is noticeably smaller than when we used the power valuations from Delgado et al. (2015). Relative to the baseline with tax credit, accounting for power using the Leard estimates reduces the percent of vehicles that payback within 16 years by about 2 percentage points. The comparable number for the Delgado estimates is 20 percentage points. This discrepancy is attributable to the difference in the estimates of average consumer willingness to pay for power.

The results do not change much when we control for both cargo space and power. To summarize, we find that approximately $68 \%$ of the HEVs we study have payback periods that extend well beyond their estimated useful life of approximately 16 years. Accounting for consumers' willingness to pay for power increases 
this number by 1-20 percentage points, depending on the estimated shadow price of power. Consequently, our results show that $12-30 \%$ of the HEVs in our study have payback periods of 16 years or less.

\subsection{Consumer heterogeneity: vehicle miles traveled and fuel price expectations}

This section describes results that account for differences across consumers. In particular, we analyze the impact of annual vehicle miles traveled (VMT) and expectations of fuel prices by defining consumers based on expected fuel price and annual vehicle miles (VMT). We also discuss the implications of other sources of consumer heterogeneity such as preference for new technology. First, we define four types of consumers that differ only in annual VMT driven; 8000, 12,000, 16,000, and $19,000 .{ }^{15}$ We rerun our analysis separately for each type of consumer under the assumption that the expected fuel price over the life of the vehicle is the same as the fuel price in the year the vehicle is released. Second, we define four types of consumers based on expected fuel price over the life of the vehicle; we used fuel prices of $\$ 2, \$ 3, \$ 4$, and $\$ 5$ per gallon. We rerun our analysis separately for each type of consumer under the assumption that annual VMT follows the scheduled published by NHTSA in the 2016 Technical Assessment Report for CAFE. Results for variation in VMT and fuel price are reported in Panels A and B of Table 5, respectively. Figures 1 and 2 report results for VMT and fuel price variation, respectively, when the vehicle price premium accounts for the shadow price of cargo space and vehicle power.

The results presented in Panel A of Table 5 allow us to comment on two points. First, how does payback vary with annual VMT? The answer to this question is predictable; payback period decreases in VMT. For example, the percent of HEVs with payback period of 1-6 years increases from $11.8 \%$ for consumers with annual VMT of 8000 to $47 \%$ for consumers with annual VMT of 19,000 in our baseline. These numbers fall to $4.6 \%$ and $16.4 \%$ when we account for Delgado's estimate of willingness to pay for horse power. The impact of annual VMT on payback period is more clearly illustrated in Figure 2 where we observe that the number of vehicles that payback within 16 years increases sharply as VMT increases even after accounting for the shadow price of cargo space and power.

Second, and more interestingly, we are able to tell which kinds of consumers should find it rational to buy each type (make/model) of HEV, all else equal.

15 We also allow for a fifth type of consumer; one who adjusts VMT over the age of the vehicle according to the VMT schedule defined by NHTSA (this is the default approach used in the paper). 


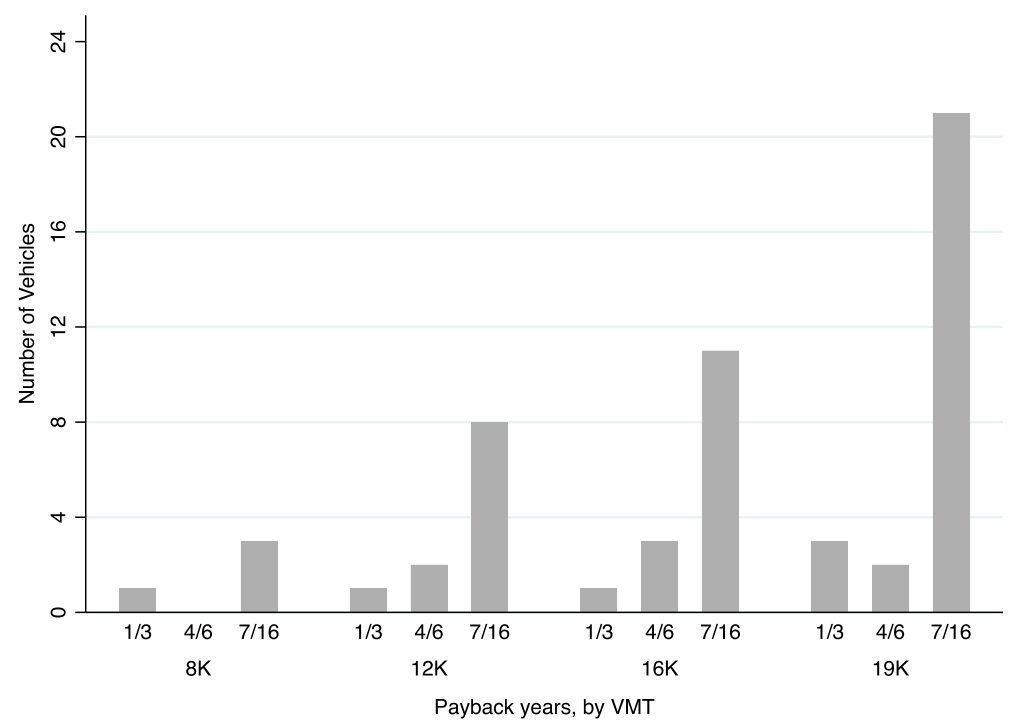

Figure 2 Payback period accounting for cargo space and power, by annual VMT.

Notes: Reported is the number of vehicles with payback periods of 1 to 3, 4 to 6, and 7 to 16 years. Each payback period is estimated with annual VMT of $8000,12,000,16,000$, and 19,000.

These results are presented in Table A1 of the Appendix. Of the 28 vehicle makes covered by our analysis, only 5 of them had HEVs whose purchase could be rationalized by people who drive 8000 miles per year. This number increases to 26 for people who drive 19,000 miles per year. Interestingly, roughly $75 \%$ of the makes we analyze cannot be rationalized in our model even for drivers who cover 19,000 miles per year. We find similar results when we allow fuel price to vary; see Panel B of Table 5, Table A2 and Figure 3. In particular, we find that the number of HEVs whose purchase can be justifiably rationalized based on our analysis increases with fuel price. Importantly, 73 of the vehicles we analyze fail to pay for themselves regardless of the expected fuel price.

The results described in this section suggest that consumers with high annual VMT or high fuel price expectations should find it in their interest to buy HEVs compared to consumers with low VMT or low fuel price expectations. It is important to note that these results do not tell us if consumers will purchase these vehicles. In this respect, a future study of consumer heterogeneity in demand for HEVs would be especially useful. It might include consumer-specific information on forecasted vehicle miles of travel, rates of time preference, perceptions of HEV repair and maintenance costs, borrowing costs, highway mileage, valuations of 
Table 5 Share of vehicles that payback within 16 years by VMT and fuel price.

\begin{tabular}{|c|c|c|c|c|}
\hline \multirow[b]{2}{*}{ Description } & \multicolumn{4}{|c|}{ Payback by VMT (share of vehicles) } \\
\hline & $8 K$ & $12 \mathrm{~K}$ & $16 K$ & $19 K$ \\
\hline Base & 11.82 & 26.36 & 41.82 & 47.27 \\
\hline Base + credit & 17.27 & 31.82 & 42.73 & 49.09 \\
\hline Base + credit + cargo & 17.27 & 31.82 & 40.00 & 46.36 \\
\hline Base + credit + power $(*)$ & 4.55 & 10.91 & 16.36 & 27.27 \\
\hline Base + credit + power $(* *)$ & 12.73 & 25.45 & 37.27 & 29.09 \\
\hline \multicolumn{5}{|c|}{ Payback by fuel price, per gallon (share of vehicles) } \\
\hline Description & $\$ 2$ & $\$ 3$ & $\$ 4$ & $\$ 5$ \\
\hline Base & 18.18 & 29.09 & 46.36 & 59.09 \\
\hline Base + credit & 24.55 & 34.55 & 48.18 & 60.00 \\
\hline Base + credit + cargo & 22.73 & 33.64 & 47.27 & 55.45 \\
\hline Base + credit + power $\left(^{*}\right)$ & 6.36 & 12.73 & 26.36 & 37.27 \\
\hline Base + credit + power $(* *)$ & 20.00 & 29.09 & 42.73 & 56.36 \\
\hline
\end{tabular}

Notes: Reported is the percent of hybrid-electric vehicles that have payback periods of 1-16 years for drivers with different annual VMT (Panel A) and expected fuel price (Panel B) indicated in column titles. Each row represents a different measure of the adjusted gross price premium. Base indicates that adjustment is made for sales taxes, loan financing costs, and insurance costs. Credit indicates adjustment for tax credits, and cargo and power indicate adjustments for the shadow price of cargo space and power, respectively. ${ }^{*}$ The shadow price of power indicated is calculated based on estimates from Delgado et al. (2015). ${ }^{* *}$ The shadow price of power indicated is calculated based on estimates from Leard et al. (2017).

performance and cargo space, beliefs about the future of fuel prices, and preference for green technology. Such a study would use actual sales data at the vehicle consumer level to determine the characteristics of consumers who buy HEVs.

We have explored only two sources of heterogeneity here. There are other sources that surely play a role in consumer choice. For example, we would expect consumer interest in $\mathrm{HEVs}$ to be greater among consumers with a strong preference for environmentally friendly technologies relative to consumers with weak environmental preferences. There is also variation in consumer preferences for owning the latest technological advances. Some consumers prefer owning the most advanced technology and are appropriately referred to as early adopters. Others are more averse to new technologies and would prefer to wait until a new technology has been proven to be reliable before they purchase and use it. Since HEVs represent one of the latest advances in propulsion technology, we should expect consumers with different attitudes toward new technology to react differently, even if their computed ownership costs are identical. Although we are not able to incorporate 


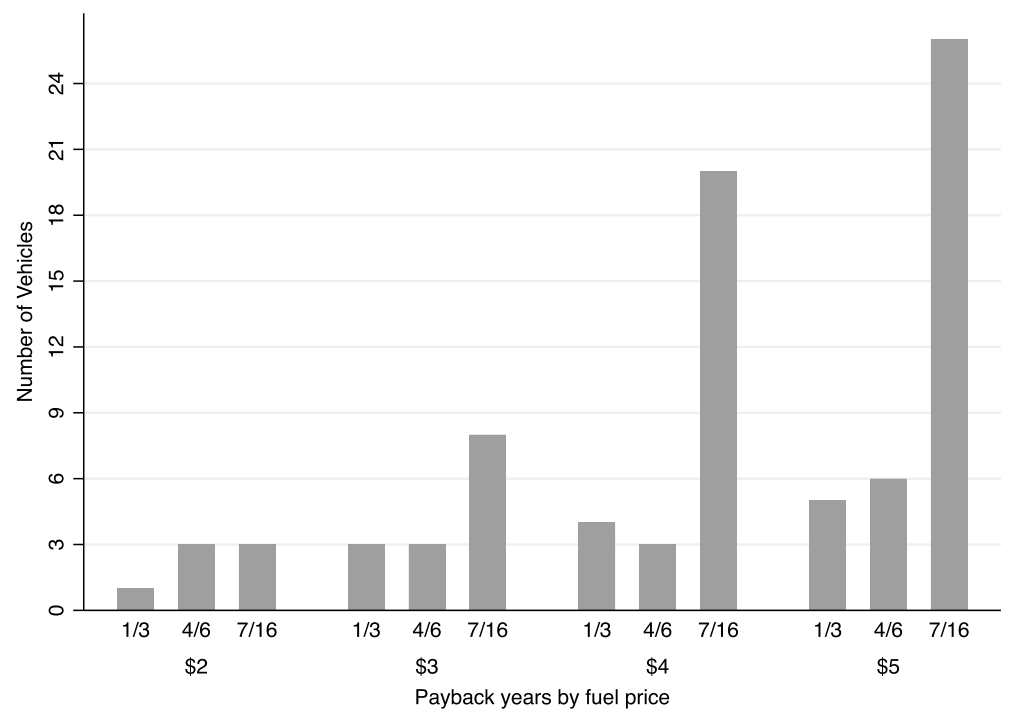

Figure 3 Payback period accounting for cargo space and power, by fuel price.

Notes: Reported is the number of vehicles with payback periods of 1 to 3, 4 to 6, and 7 to 16 years. Each payback period is estimated with fuel prices of $2,3,4$, and 5 .

these consumer preferences in the total cost of ownership calculations, we are not suggesting that such preferences are non-rational or irrational. They may certainly help explain why some HEVs are purchased (even when they appear to be a poor buy) and why other HEVs are not purchased (even when they appear to be a good buy).

\subsection{Vehicle heterogeneity: model year, weight and manufacturer}

This section describes variation in payback periods across vehicle characteristics. We provide evidence on model year, vehicle weight and vehicle manufacturer.

Model year. Our results suggest that more recent HEVs have a much shorter payback period, which should make them more appealing to consumers. In particular, we find that 20 of the $29 \mathrm{HEVs}$ with payback periods less than 16 years are from MY 2016 to 2017 in our baseline; the remaining vehicles are spread out evenly across MY 2010-2014. Additionally, 9 of the $10 \mathrm{HEVs}$ with payback periods of 16 years are from MY 2016 to 2017. Similarly, 7 of the 13 vehicles that pay back 
within 16 years when we account for power and tax credits are from MY 2016 with the remaining 6 vehicles coming from MYs 2007, 2008 and 2010. Additionally, all of the vehicles that pay back within 6 years are from MY2016.

Vehicle make. We find that the results also vary across vehicle make. For example, 19 of the 29 vehicles with payback periods less than 16 years in the baseline are produced by only 4 manufacturers (Acura, Ford, Nissan, and Toyota). This number drops to 2 when we account for power and tax credit; 8 of the 13 vehicles with payback periods less than 16 years are produced by the two manufacturers (Ford and Mazda).

Vehicle weight. We find that the mean vehicle weight in our sample is 4260 pounds. Interestingly, there is no meaningful variation in vehicle weight among vehicles that have payback periods below 30 years in the baseline; these vehicles weigh approximately 3800 pounds on average. However, vehicles with payback periods of $30+$ years weigh 4400 pounds on average. Results are very comparable for the other specifications; vehicles with payback periods above 30 years weigh more than vehicles with payback periods below 30 years.

\subsection{Upgrades and drivability}

The long payback period for an investment in an HEV suggests that choosing their gasoline comparators is a rational move for many consumers. In fact, our results suggest that, for the majority of HEVs in our study, poor sales performance of HEVs is consistent with a rational model of consumer behavior. However, the rational model of behavior remains questionable for the $12 \%-32 \%$ of HEVs that have payback periods of less than 16 years. Opting not to purchase a vehicle that pays for itself within the vehicle's expected life suggests to us that either consumers do not value these fuel savings or there are other factors at play that we have not accounted for. This section describes two omitted factors that might explain the low take-up of HEVS.

Upgrades. A contender for omitted variables is upgrades such as entertainment and safety packages. Because it is difficult to estimate a shadow price for these upgrades, we collected information on the upgrades and discuss their prevalence among HEVs relative to their gasoline comparators. We find that HEVs almost always have at least the same set of upgrades as their gasoline comparators and in many instances are equipped with richer upgrade packages than offered on their gasoline comparators. Therefore, while we are unable to monetize these upgrades, they are an unlikely explanation for why consumers chose not to buy HEVs. In other 
words, monetizing these upgrades would most likely reduce the payback period of these HEVs, thus further weakening the case for a rational explanation of low sales.

Drivability. Another omitted variable focuses on drivability issues (e.g., braking and handling) that may arise due to regenerative braking systems or a noticeable transition between electric and gasoline propulsion. We collected data from consumer-facing expert auto reviews for a subsample of HEVs to document the extent to which consumers might express subjective concerns about driving HEVs. In particular, we search the reviews for disadvantages of the HEVs. Our focus on negative comments is motivated by the fact that we are trying to explain why consumers do not buy vehicles that presumably pay for themselves; this analysis is limited to the $12 \%(=13 / 110)$ of HEVs that have payback periods less than 16 years after accounting for the shadow price of power (Delgado et al., 2015). The reviews are taken from Edmunds, US News and World Report, USA Today, and Car and Driver; the results are summarized in Table 6 below.

Table 6 documents six dimensions of drivability and the number of HEVs for which each dimension received a negative review. The results show that braking appears to be a concern with some HEVs. Reviewers report that five of the HEVs had brakes that felt artificial, sensitive, or stiff. There is also some concern about handling and acceleration noise, particularly during the transition between gasoline and electric power. If these features of the driving experience are highly valued and if consumer perceptions of HEVs influenced or mirrored by expert reviews, then it is possible that drivability differences between HEVs and their gasoline comparators could partly explain the low sales, despite the favorable payback period. Such drivability differences could explain the preferences of some consumers for some of the 13 HEVs. ${ }^{16}$

In most cases, however, the expert reviews do not raise the drivability issues as reasons not to purchase the HEV. Indeed, the expert reviews of HEVs are often quite favorable with regard to purchasing recommendation, particularly the 13 mentioned here. What reviewers are doing is sensitizing readers to how the drive of an HEV may feel subtly different and may take a period of time to get used to. The subtle nature of the differences is underscored by the fact that not all of the reviewers raised the same drivability issues. More research is needed to determine how important drivability issues are as consumers decide whether to consider or purchase an HEV. Many consumers may reject HEVs before they even consider drivability issues.

16 These are the Audi Q5, Chevrolet Malibu, Ford Escape, Ford Fusion, Mazda Tribute, Mercury Milan, RAV 4, and the Infiniti M. 
Table 6 Drivability issues with HEVs noted by expert consumer-facing car reviewers.

\begin{tabular}{|c|c|c|c|}
\hline Reviewer comment & $\begin{array}{l}\text { Number of } \\
\text { vehicles }\end{array}$ & Vehicles & Commentator \\
\hline \multirow{2}{*}{ Brakes feel artificial } & \multirow[t]{2}{*}{2} & 2016 Ford Fusion & Edmunds/US News \\
\hline & & 2016 RAV 4 & Edmunds/US News/Car and Driver \\
\hline \multirow{2}{*}{ Brakes sensitive } & \multirow[t]{2}{*}{2} & 2016 Ford Fusion & US News \\
\hline & & 2012 Infiniti M & US News \\
\hline \multirow{2}{*}{ Stiff brakes } & \multirow[t]{2}{*}{2} & 2007 Ford Escape & Edmunds \\
\hline & & 2008 Mazda Tribute & Edmunds \\
\hline & 3 & 2016 Ford Fusion & Edmunds \\
\hline \multirow[t]{3}{*}{ Acceleration noise } & & 2016 Chevy Malibu & US News/USA Today \\
\hline & & 2007 Ford Escape & Edmunds/Cars.com \\
\hline & 2 & 2010 Ford Fusion & US News \\
\hline Less nimble & & 2008 Mazda Tribute & Edmunds \\
\hline Steering is numb & 1 & 2016 RAV 4 & US News \\
\hline $\begin{array}{l}\text { Noticeable transition between } \\
\text { gas/electric power }\end{array}$ & 1 & 2012 Infiniti M & Car and Driver \\
\hline
\end{tabular}

Notes: These comments are pulled from reviews of 13 HEVs that have payback periods of 1-16 years after accounting for the shadow price of power estimated in Delgado et al. (2015).

\subsection{Selected case studies of specific HEVs}

Here we present four short case studies of specific HEVs with payback periods less than 16 years and highly favorable expert reviews but low purchase rates. Taken together, the five case studies cover several vehicle classes and manufacturers.

2017 Ford Fusion Hybrid. The Ford Fusion is a popular midsized 4-door sedan with a combined EPA rating of 42 miles per gallon. The first-generation Fusion Hybrid was offered in 2010; the current generation began in 2013, with only modest refinements since then. We estimate consumer payback periods of 1 year (titanium trim), 6 years (SE trim) and 8 years (S trim). Drawbacks: some (but not all) reviews raise subtle drivability issues (e.g., the feel of the regenerative brakes). For several months in 2017, the Fusion Hybrid outsold the Toyota Prius (Cobb, 2017). Nonetheless, only $11.24 \%$ of Fusion buyers are choosing the hybrid version.

2017 Chevrolet Malibu Hybrid. The Malibu is a popular midsized 4-door sedan that competes with the Fusion. The Malibu Hybrid was first offered in 2016 with an EPA combined rating of 46 miles per gallon (front-wheel drive). We estimate the payback period at 8 years. The expert reviews are highly favorable. Drivability is notably good: smooth transitions from electric to gasoline power and regenerative brakes that feel like regular brakes. Drawbacks: offered in only one trim, though it 
is loaded with special features, and the trunk is undersized. Only 1.9\% of Malibu buyers are choosing the Malibu Hybrid.

2008 Ford Escape Hybrid. Through a licensing arrangement with Toyota, Ford offered the first hybrid SUV in 2004 and refined the design for 2008-2012. The combined EPA mileage rating was 34 miles per gallon (front-wheel drive); 31 miles per gallon (all-wheel drive). We estimate the consumer payback periods at 12 years (base trim, all-wheel drive) and 11 years (base trim, front-wheel drive). Ford responded to consumer concerns by smoothing out the engine's stop-start feature, fine tuning the regenerative brakes so that they feel more like regular hydraulic brake systems, and enhancing horsepower without compromising fuel economy. In 2008 about $10.8 \%$ of Escape customers $(17,173)$ chose the hybrid version. The Escape Hybrid was terminated starting model year 2013.

2017 Toyota RAV4 Hybrid. The RAV4 is a popular compact cross-over vehicle that, starting in 2016, was offered with a hybrid option for the first time. The combined EPA mileage rating is 33 miles per gallon for front-wheel drive; 29 miles per gallon for all-wheel drive. We estimate the consumer payback periods at 3 years for both the XLE and Limited versions (front-wheel drive). Compared to the gasolinepowered RAV4, the Hybrid has greater rated horsepower, greater low-speed torque, and faster times from 0 to 60 miles per hour. The expert reviews are highly favorable. Drawbacks: there is a slight loss of trunk space and some (but not all) reviews raise drivability concerns. In its first year (2016), the hybrid option accounted for about 13\% (45,097) of total RAV sales, despite a price premium of less than $\$ 1000$ (Zola, 2017).

\section{Policy implications and conclusion}

Our results show that the average consumer is unlikely to find it worth her while to purchase most of the HEVs in our sample. This is not to say that some consumers will not purchase HEVs. In fact, our analysis suggests that consumers who drive many miles per year or have high fuel price expectations might find that HEVs are a good buy. We also expect HEVs to be popular among consumers who like to adopt the latest vehicle technology as well as those who are environmentally friendly. However, these kinds of preferences/characteristics are unlikely to be representative of the average or even the median consumers. Therefore, one possible explanation for the positive but low market share enjoyed by HEVs is that there are not enough consumers for whom most HEVs are a good deal.

So, if most HEVs are not a good deal for consumers, why are vehicle manufacturers offering them? We can only speculate. Some offerings may be intended as an experiment, to discern the extent of consumer demand that might exist (e.g., LaReau, 2011 on the pricing of the Lincoln MKZ Hybrid). Some manufacturers 
may perceive HEV offerings as useful in boosting the public image of the company, even though they do not sell well. Some manufacturers may see HEV offerings as a technique to enhance their average CAFE compliance numbers or to prepare for future years when CAFE constraints may become binding (e.g., see Iliff, 2018 on why CAFE considerations might be inducing Lexus to sell HEVs at a loss). In any event, it is well known that marginal cost and price are not tightly connected in the auto industry, especially in the short run (Gron \& Swenson, 2000).

The federal government's CAFE standards generate some social benefits in the form of reduced pollution (e.g., the greenhouse gases linked to climate change), but the costs of stricter CAFE standards are sufficiently large that they may not be justified by consideration of environmental benefits alone (NHTSA, 2012; EPA, 2012; TAR, 2016). The climate-related benefits are particularly uncertain because they depend on the highly uncertain estimates of the social cost of carbon (Interagency Working Group, 2016; NRC, 2017; Morgan et al., 2017). Indeed, about 80\% of the predicted benefits of CAFE standards come in the form of gasoline savings to the private consumer; and it is those private benefits that drive the favorable benefitcost results reported in support of CAFE standards (NHTSA, 2012; EPA, 2012; TAR, 2016; Gayer \& Viscusi, 2013; Helfand \& Dorsey-Palmateer, 2015). CAFE aims to capture those private benefits for consumers by establishing performance standards that require manufacturers to invest in fuel-saving technologies such as improved engines and transmissions and hybridization, though some evidence suggests automakers also respond by compromising performance (Klier \& Linn, 2012). The pro-regulation logic is that CAFE regulation is justified by the consumer's $e x$ post "experienced utility" even though the investments are not made voluntarily by consumers at the time of vehicle purchase, the "decision utility" perspective (Kahneman \& Sugden, 2005; Fischer et al., 2007; Gillingham \& Palmer, 2014; Helfand \& Dorsey-Palmateer, 2015).

The agencies' engineering-economic studies originally suggested that widespread hybridization would not be necessary for manufacturers to comply with the 2017-2025 federal standards, since more cost-effective compliance alternatives are available (NHTSA, 2012; EPA, 2012; NRC, 2015a). However, the recent compliance modeling performed by NHTSA projects that more hybridization will be necessary than is projected by EPA (TAR, 2016). Moreover, some vehicle classes (e.g., performance-oriented sedans) and vehicle manufacturers (e.g., Mercedes-Benz and BMW) may be compelled to invest in significant hybridization, given their current fleet mix. Even if vehicle manufacturers do not invest in full hybridization, some of the elements of HEVs (e.g., regenerative breaking and stop-start systems) may be attractive compliance options for regulated manufacturers (German, 2015).

The regulatory ramifications suggest that some priority should be given to extending the line of research that we have executed in this paper. It is important to understand whether the limited commercial success of hybrids is attributable 
to rational choice (given low fuel prices in the U.S.) or non-rational behaviors by consumers.

One extension of our study would be to undertake a similar analysis in Japan, where average fuel prices are approximately $\$ 4.50$ per gallon, the government subsidized HEV purchases until 2012, and HEVs account for 35\% of conventional passenger vehicle sales (Osuga, 2017; Japan Automobile Manufacturers Association, Inc., 2017). A better understanding of the Japanese situation could shed light on the low rate of HEV penetration in the U.S. and Europe. The European market is a less promising area of study because the diesel-powered car has, until the recent Volkswagen scandal, been dominating the light-duty market.

Another extension would be to build on the recent experiments of Allcott and Knittel (2017) by focusing on consumers who are likely to purchase a model that has both a gasoline and hybrid offering. A combination of stated-preference and revealed-preference studies could add additional insight into why relatively few consumers choose the hybrid, even when the total cost of ownership of the hybrid is attractive. Some social science research on how "hybrids" are perceived by consumers might also be useful, coupled with informational interventions. A key issue is how receptive consumers are to new information about HEVs that challenges their prior beliefs.

Finally, further extensions should examine heterogeneity in consumer characteristics (e.g., miles driven per year, share of miles driven in congested inner-city traffic, higher borrowing costs for subprime buyers, and variable time preferences), state-level variation in gasoline prices (about $\$ 1.00$ per gallon larger in California than the US national average, primarily due to tax differences), and variable perceptions of future gasoline prices, future maintenance and repair expenses for vehicles, and safety risks. Without a complete analysis of heterogeneity, it is possible to conclude erroneously that consumer undervaluation of fuel savings is present (Bento et al., 2012).

Acknowledgments: The authors acknowledge helpful comments and suggestions from John German, Gloria Helfand, Ryan Keefe, Joshua Linn, Wally Wade, and two anonymous reviewers. We also want to thank the Alliance of Automobile Manufacturers for providing financial support. All aspects of the research design, execution, and analysis, were performed independently from the funders. The authors are fully responsible for the research design, analysis, and conclusions.

\section{Supplementary material}

To view supplementary material for this article, please visit https://doi.org/10.1017 /bca.2018.24. 


\section{References}

Al-Alawi, Baha M. and Thomas H. Bradley. 2013. "Total Cost of Ownership, Payback, and Consumer Preference Modeling of Plug-in Hybrid Electric Vehicles.” Applied Energy, 103: 488-506.

Allcott, Hunt. 2013. "The Welfare Effects of Misperceived Product Costs: Data and Calibrations from the Automobile Market." American Economic Journal: Economic Policy, 5(3): 30-66.

Allcott, Hunt and Michael Greenstone. 2012. "Is There an Energy Efficiency Gap?" Journal of Economic Perspectives, 26(1): 3-28.

Allcott, Hunt and Christopher Knittel. 2017. "Are consumers poorly informed about fuel economy? Evidence from two experiments.” Working Paper 23076. National Bureau of Economic Research.

Allcott, Hunt, Sendhil Mullainathan, and Dmitry Taubinsky. 2014. "Energy Policy with Externalities and Internalities." Journal of Public Economics, 112: 72-88.

Allcott, Hunt and Nathan Wozny. 2014. "Gasoline Prices, Fuel Economy, and the Energy Paradox." The Review of Economics and Statistics, 96(5): 779-795.

Anderson, Soren T., Ryan Kellogg, and James M. Sallee. 2013. "What Do Consumers Believe about Future Gasoline Prices?” Journal of Environmental Economics and Management, 66(3): 383-403.

Anderson, Soren T., Ryan Kellogg, James M. Sallee, and Richard T. Curtin. 2011. "Forecasting Gasoline Prices Using Consumer Surveys." American Economic Review, 101(3): $110-114$.

Bento, Antonio M., Shanjun Li, and Kevin Roth. 2012. "Is There an Energy Paradox in Fuel Economy? A Note on the Role of Consumer Heterogeneity and Sorting Bias." Economics Letters, 115(1): 44-48.

Beresteanu, Arie and Shanjun Li. 2011. "Gasoline Prices, Government Support, and the Demand for Hybrid Vehicles in the United States*." International Economic Review, 52(1): 161-182.

Blumstein, Carl and Margaret Taylor. 2013. "Rethinking the energy-efficiency gap: producers, intermediaries, and innovation." Discussion Paper. Energy Institute at Haas. University of California-Berkeley.

Board of Governors of the Federal Reserve System (US). 2017. "Finance Rate on Consumer Installment Loans at Commercial Banks, New Autos 60 Month Loan.” FRED, Federal Reserve Bank of St. Louis. August 1, 2017.

Brinson, Linda C. 2018. “Are Hybrid Car Maintenance Costs Higher?” Howstuffworks.

Busse, Meghan R., Christopher R. Knittel, and Florian Zettelmeyer. 2013. "Are Consumers Myopic? Evidence from New and Used Car Purchases." American Economic Review, 103(1): 220-256.

Busse, Meghan R., Jorge Silva-Risso, and Florian Zettelmeyer. 2006. “\$1000 Cash Back: The Pass-Through of Auto Manufacturer Promotions." The American Economic Review, 96(4): 1253-1270.

Camilleri, Adrian R. and Richard P. Larrick. 2014. "Metric and Scale Design as Choice Architecture Tools." Journal of Public Policy \& Marketing, 33(1): 108-125.

Carley, Sanya, Denvil Duncan, John D. Graham, Saba Siddiki, and Nikolaos Zirogiannis. 2017. "A Macroeconomic Study of Federal and State Auto Regulations with Recommendations for Analysts, Regulators, and Legislators”. 
Center for Automotive Research [CAR]. 2011. "The U.S. Automotive Market and Industry in 2025 ".

Chandra, Ambarish, Sumeet Gulati, and Milind Kandlikar. 2010. "Green Drivers or Free Riders? An Analysis of Tax Rebates for Hybrid Vehicles." Journal of Environmental Economics and Management, 60(2): 78-93.

Cobb, Jeff. 2017. "Has Been The Year Of The Toyota Prius' Decline." Available at https: //www.hybridcars.com/2017-has-been-the-year-of-the-toyota-prius-decline/. (accessed September 16, 2018).

Consumer's Union. 2015. “Are Green Cars Still Worth the Money?” Available at https://ww w.consumerreports.org/cro/magazine/2015/04/are-green-cars-still-worth-the-money/in dex.htm. (accessed September 16, 2018).

Delgado, Michael S., Jessica L. Harriger, and Neha Khanna. 2015. "The Value of Environmental Status Signaling." Ecological Economics, 111: 1-11.

DeMuro, Doug. 2013. "Is a Hybrid Car Worth the Extra Money?" Available at http://www.au totrader.com/car-tips/is-a-hybrid-car-worth-the-extra-money-215304. (accessed February 9,2017$)$.

Diamond, David. 2009. "The Impact of Government Incentives for Hybrid-Electric Vehicles: Evidence from US States." Energy Policy, 37(3): 972-983.

Dublin, Jon. 2012. "Are Hybrid Cars Worth It? The Answer May Surprise You." Available at https://www.moneysmartguides.com/are-hybrid-cars-worth-the-price. (accessed September 16, 2018).

Duffer, Robert. 2014. "Do Hybrid Cars Save Money? - Chicago Tribune." Available at http: //www.chicagotribune.com/autos/ct-xpm-2014-06-12-chi-do-hybrid-cars-save-money20140612-story.html. (accessed September 16, 2018).

Dumortier, Jerome, Saba Siddiki, Sanya Carley, Joshua Cisney, Rachel M. Krause, Bradley W. Lane, John A. Rupp, and John D. Graham. 2015. "Effects of Providing Total Cost of Ownership Information on Consumers' Intent to Purchase a Hybrid or Plug-in Electric Vehicle." Transportation Research Part A: Policy and Practice, 72: 71-86.

Edmunds.com. 2017. "2016 Hybrid Buying Guide: Top Recommended Hybrid Cars." Available at https://www.edmunds.com/hybrid/2016/buying-guide.html. (accessed September 16, 2018).

Environmental Protection Agency, and National Highway Traffic Safety Administration. 2011. "Revisions and Additions to Motor Vehicle Fuel Economy Label: Response to Comments." EPA-HQ-OAR-2009-0865.

Environmental Protection Agency. 2012. "Regulatory Impact Analysis: Final Rulemaking for 2017-2025 Light-Duty Vehicle Greenhouse Gas Emission Standards and Corporate Average Fuel Economy Standards.” EPA-420-R-12-016. Washington, DC.

Fischer, Carolyn, Winston Harrington, and Ian W. H. Parry. 2007. "Should Automobile Fuel Economy Standards Be Tightened?” Energy Journal, 28(4): 1-29.

Gallagher, Kelly Sims and Erich Muehlegger. 2011. "Giving Green to Get Green? Incentives and Consumer Adoption of Hybrid Vehicle Technology." Journal of Environmental Economics and Management, 61(1): 1-15.

Gayer, Ted and W. Kip Viscusi. 2013. "Overriding Consumer Preferences with Energy Regulations." Journal of Regulatory Economics, 43(3): 248-264.

German, John. 2015. "Hybrid Vehicles: Technology Development and Cost Reduction." Technical Brief No. 1. Washington, DC: International Council on Clean Transportation.

Gillingham, Kenneth and Karen Palmer. 2014. "Bridging the Energy Efficiency Gap: Policy Insights from Economic Theory and Empirical Evidence." Review of Environmental Economics and Policy, 8(1): 18-38. 
Gilmore, Elisabeth A. and Lester B. Lave. 2013. "Comparing Resale Prices and Total Cost of Ownership for Gasoline, Hybrid and Diesel Passenger Cars and Trucks." Transport Policy, 27: 200-208.

Greene, David L. 2010. "How Consumers Value Fuel Economy: A Literature Review," Available at https://trid.trb.org/view/920593. (accessed September 16, 2018).

Greene, David L. 2011. "Uncertainty, Loss Aversion, and Markets for Energy Efficiency." Energy Economics, Special Issue on The Economics of Technologies to Combat Global Warming, 33(4): 608-616.

Greene, David L., David H. Evans, and John Hiestand. 2013. "Survey Evidence on the Willingness of U.S. Consumers to Pay for Automotive Fuel Economy." Energy Policy, 61: 1539-1550.

Greene, David L. and Jilleah G. Welch. 2016. "The Impact of Increased Fuel Economy for Light Vehicles on the Distribution of Income in the United States." Baker Report 5:16. University of Tennessee: The Howard H Baker Jr. Center for Public Policy.

Greimel, Hans. 2015. "Why Toyota Offers 2 Battery Choices in next Prius." Available at ht tp://www.autonews.com/article/20151128/COPY/311289998/why-toyota-offers-2-batt ery-choices-in-next-prius. (accessed September 16, 2018).

Grigolon, Laura, Mathias Reynaert, and Frank Verboven. 2014. "Consumer Valuation of Fuel Costs and the Effectiveness of Tax Policy: Evidence from the European Car Market." SSRN Scholarly Paper ID 2533972. Rochester, NY: Social Science Research Network.

Gron, Anne and Deborah L. Swenson. 2000. "Cost Pass-Through in the U.S. Automobile Market." The Review of Economics and Statistics, 82(2): 316-324.

Gulati, Sumeet, Carol McAusland, and James M. Sallee. 2017. "Tax Incidence with Endogenous Quality and Costly Bargaining: Theory and Evidence from Hybrid Vehicle Subsidies." Journal of Public Economics, 155: 93-107.

Hausman, Jerry A. 1979. "Individual Discount Rates and the Purchase and Utilization of Energy-Using Durables.” Bell Journal of Economics, 10(1): 33-54.

Healey, James R. 2014. "Ford Cuts MPG Ratings on Some Autos." Available at https://w ww.usatoday.com/story/money/cars/2014/06/12/ford-gas-mileage-lowered/10383307/. (accessed September 16, 2018).

Heffner, Reid R., Kenneth S. Kurani, and Thomas S. Turrentine. 2007. "Symbolism in California's Early Market for Hybrid Electric Vehicles." Transportation Research Part D: Transport and Environment, 12(6): 396-413.

Helfand, Gloria and Reid Dorsey-Palmateer. 2015. "The Energy Efficiency Gap in EPA's Benefit-Cost Analysis of Vehicle Greenhouse Gas Regulations: A Case Study." Journal of Benefit-Cost Analysis, 6(2): 432-454.

Helfand, Gloria, Michael McWilliams, Kevin Bolon, Lawrence Reichle, Mandy Sha, Amanda Smith, and Robert Beach. 2016. "Searching for Hidden Costs: A Technology-Based Approach to the Energy Efficiency Gap in Light-Duty Vehicles." Energy Policy, 98: 590-606.

Helfand, Gloria and Ann Wolverton. 2011. "Evaluating the Consumer Response to Fuel Economy: A Review of the Literature." International Review of Environmental and Resource Economics, 5(2): 103-146.

Hirsch, Jerry. 2015. "Honda Accord Beats Toyota Prius as Top Seller in California." Available at https://www.latimes.com/business/autos/la-fi-hy-accord-prius-20150214-story. html. (accessed September 16, 2018).

Iliff, Laurence. 2018. "Lexus Testing New Hybrid Math.” Automotive News. February 19, 2018. http://www.autonews.com/article/20180219/RETAIL01/180219776/lexus-newhybrid-premium. 
Interagency Working Group on Social Cost of Carbon. 2016. "Technical Support Document: Technical Update of the Social Cost of Carbon for Regulatory Impact Analysis under Executive Order 12866." In Social Cost of Carbon Estimates for Regulatory Impact Analysis: Development and Technical Assessment, 65-88.

Internal Revenue Service. 2009. "Tax Credit for Ford Hybrids Begins Phase Out." Available at https://www.irs.gov/newsroom/tax-credit-for-ford-hybrids-begins-phase-out. (accessed September 16, 2018).

Jaffe, Adam B. and Robert N. Stavins. 1994. "The Energy Paradox and the Diffusion of Conservation Technology." Resource and Energy Economics, 16(2): 91-122.

Japan Automobile Manufacturers Association, Inc. 2017. The Motor Industry of Japan 2017, 26.

Jenn, Alan, Inês L. Azevedo, and Pedro Ferreira. 2013. "The Impact of Federal Incentives on the Adoption of Hybrid Electric Vehicles in the United States." Energy Economics, 40: 936-942.

Kahn, Matthew E. 2007. "Do Greens Drive Hummers or Hybrids? Environmental Ideology as a Determinant of Consumer Choice." Journal of Environmental Economics and Management, 54(2): 129-145.

Kahneman, Daniel, Paul Slovic, and Amos Tversky. 1982. Judgment Under Uncertainty: Heuristics and Biases. Cambridge University Press.

Kahneman, Daniel and Robert Sugden. 2005. "Experienced Utility as a Standard of Policy Evaluation." Environmental and Resource Economics, 32(1): 161-181.

Klier, Thomas and Joshua Linn. 2012. "New-Vehicle Characteristics and the Cost of the Corporate Average Fuel Economy Standard.” The RAND Journal of Economics, 43(1): 186-213.

KRT. 2005. "Tax Credit Adds Incentive to Buy Hybrid Vehicles." Available at http://w ww.chicagotribune.com/news/ct-xpm-2005-08-24-0508240393-story.html. (accessed September 16, 2018).

Lacetera, Nicola, Devin G. Pope, and Justin R. Sydnor. 2012. "Heuristic Thinking and Limited Attention in the Car Market." American Economic Review, 102(5): 2206-2236.

LaReau, Jamie. 2011. "Ford Brings Hybrid Technology In-House." Available at http://www. autonews.com/article/20110425/OEM06/304259984/ford-brings-hybrid-technology-in -house. (accessed September 16, 2018).

Larrick, Richard P. and Jack B. Soll. 2008. "The MPG Illusion.” Science, 320(5883): 1593-1594.

Leard, Benjamin, Joshua Linn, and Yichen Christy Zhou. 2017. "How Much Do Consumers Value Fuel Economy and Performance? Evidence from Technology Adoption.” Available at http://www.rff.org/research/publications/how-much-do-consumers-value-fuel-e conomy-and-performance-evidence-technology. (accessed September 16, 2018).

Liu, Yizao. 2014. "Household Demand and Willingness to Pay for Hybrid Vehicles." Energy Economics, 44: 191-197.

Mannix, Brian F. and Susan E. Dudley. 2015. "The Limits of Irrationality as a Rationale for Regulation.” Journal of Policy Analysis and Management, 34(3): 705-712.

McConnell, Virginia. 2013. "The new CAFE standards: Are they enough on their own?" Discussion Paper 13-14. Washington, DC: Resources for the Future.

McConnell, Virginia and Tom Turrentine. 2010. "Should Hybrid Vehicles Be Subsidized?" Washington, DC: Resources for the Future. 
McCormick, John. 2015. "Car Culture: King of Hybrids Prius Gets Royal Makeover.” Available at https://www.detroitnews.com/story/business/columnists/john-mccormick/2015/ 11/18/mccormick-prius-makeover-hybrid-toyota/76028006/. (accessed September 16, 2018).

McVeigh, Paul. 2016. "Toyota Pitches Hybrids in Diesel Country." Automotive News, June 20, 2016. http://www.autonews.com/article/20160620/OEM05/306209993/toyota-pitc hes-hybrids-in-diesel-country.

Morgan, M. Granger, Parth Vaishnav, Hadi Dowlatabadi, and Ines L. Azevedo. 2017. "Rethinking the Social Cost of Carbon Dioxide." Issues in Science and Technology, 33(4).

Mullaney, Tim. 2015. "Why You Should Still Buy a Hybrid Car." Available at https://www .marketwatch.com/story/why-you-should-still-buy-a-hybrid-car-2015-06-11. (accessed September 16, 2018).

National Highway Traffic Safety Administration. 2012. "Final Regulatory Impact Analysis - Corporate Average Fuel Economy for MY 2017-2025 Passenger Cars and Light Trucks.” National Highway Traffic Safety Administration.

National Research Council. 2015a. Cost, Effectiveness, and Deployment of Fuel Economy Technologies for Light-Duty Vehicles. Washington, DC: National Academies Press.

National Research Council. 2015b. Overcoming Barriers to Deployment of Plug-in Electric Vehicles. Washington, DC: National Academies Press.

National Research Council. 2017. Valuing Climate Damages: Updating Estimation of the Social Cost of Carbon Dioxide. Washington, DC: National Academies Press.

Nelson, Gabe. 2013. "Flawed Rules, MPG Rivalry Set the Stage for C-Max Episode." Available at http://www.autonews.com/article/20130817/OEM11/308199941. (accessed September 16, 2018).

Newell, Allen, John C. Shaw, and Herbert A. Simon. 1958. "Elements of a Theory of Human Problem Solving." Psychological Review, 65(3): 151-166.

Nixon, Hilary and Jean-Daniel Saphores. 2011. "Understanding Household Preferences for Alternative-Fueled Vehicle Technologies." Technical Report. Mineta Transportation Institute. MTI Report 10-11. San Jose State University. San Jose, CA. June.

NPR. 2007. "Access to Calif. HOV Lane Puts Premium on Hybrids." Available at https://ww w.npr.org/templates/story/story.php?storyId=9626745. (accessed September 16, 2018).

Ohnsman, Alan. 2014. "Toyota's Prius Keeps Top California Sales Rank, Tesla Gains." Available at https://www.bloomberg.com/news/articles/2014-02-13/toyota-prius-keeps -top-california-sales-rank-as-tesla-moves-up. (accessed September 16, 2018).

Osuga, Ryuji. 2017. Environment Department. Japan Automobile Manufacturers Association, Inc. June 29, personal communication.

Ozaki, Ritsuko and Katerina Sevastyanova. 2011. "Going Hybrid: An Analysis of Consumer Purchase Motivations.” Energy Policy, 39(5): 2217-2227.

Popiel, Stephen. 2011. "From Nozzle to Plug: Achieving Zero Emissions." SAE 2011 Hybrid Vehicle Symposium. Anaheim, CA. February 9-11.

Rechtin, Mark. 2007. "Study: For Some, Prius Is a Luxury Alternative.” Available at http:// www.autonews.com/article/20070423/SUB/70420015/study:-for-some-prius-is-a-luxu ry-alternative. (accessed September 16, 2018).

Robinson, Lisa A. and James K. Hammitt. 2011. "Behavioral Economics and the Conduct of Benefit-Cost Analysis: Towards Principles and Standards." Journal of Benefit-Cost Analysis, 2(2): 1-51.

Sallee, James M. 2011. "The Surprising Incidence of Tax Credits for the Toyota Prius." American Economic Journal: Economic Policy, 3(2): 189-219. 
Sallee, James M. 2014. "Rational Inattention and Energy Efficiency." The Journal of Law \& Economics, 57(3): 781-820.

Sallee, James M., Sarah E. West, and Wei Fan. 2016. "Do Consumers Recognize the Value of Fuel Economy? Evidence from Used Car Prices and Gasoline Price Fluctuations." Journal of Public Economics, 135: 61-73.

Saulsbury, Bo, Janet L. Hopson, David L. Greene, and Robert Gibson. 2015. "Status and Issues for Consumer Fuel Economy in the United States." Report prepared for US Department of Energy. Oak Ridge National Laboratory. Oak Ridge, Tennessee. February.

Schewel, Laura and Daniel M. Kammen. 2010. "Smart Transportation: Synthesizing Electrified Vehicles and Mobile Information Systems. Environment".

Sexton, Steven E. and Alison L. Sexton. 2014. "Conspicuous Conservation: The Prius Halo and Willingness to Pay for Environmental Bona Fides.” Journal of Environmental Economics and Management, 67(3): 303-317.

Shewmake, Sharon and Lovell Jarvis. 2014. "Hybrid Cars and HOV Lanes." Transportation Research Part A: Policy and Practice, 67: 304-319.

Simon, Herbert A. 1976. Administrative Behavior: A Study of Decision-Making Processes in Administrative Organization (3rd ed.). New York, NY, US: Free Press.

Small, Kenneth A. 2010. "Energy policies for automobile transportation: a comparison using the National Energy Modeling System.” Discussion Paper. University of CaliforniaIrvine.

Technical Assessment Report. [TAR], Environmental Protection Agency [EPA], National Highway Traffic Safety Administration [NHTSA], California Air Resources Board [CARB] (2016). Draft Technical Assessment Report: Midterm Evaluation of LightDuty Vehicle Greenhouse Gas Emission Standards and Corporate Average Fuel Economy Standards for Model Years 2022-2025. EPA-420-D-16-900.

Thaler, Richard H. and Cass R. Sunstein. 2008. Nudge: Improving Decisions About Health, Wealth, and Happiness. Yale University Press.

Truett, Richard. 2016. "Why Hybrids Should Be the Standard." Automotive News. Available at http://www.autonews.com/article/20160229/OEM05/302299983/why-hybrids-shoul d-be-the-standard. (accessed March 12, 2016).

Turrentine, Thomas S. and Kenneth S. Kurani. 2007. "Car Buyers and Fuel Economy?" Energy Policy, 35(2): 1213-1223.

Undercoffler, David. 2015. "Next-Gen Prius May Be Ill-Timed, But Not Ill-Fated." Available at http://www.autonews.com/article/20150629/OEM05/306299997/next-gen-priu s-may-be-ill-timed-but-not-ill-fated. (accessed March 12, 2016).

Wards Automotive. 2018. "Europe Warming Up to Hybrids More Quickly than U.S." Available at https://www.wardsauto.com/engines/hybrid-sales-set-record-2017-evs-gain-gro und. (accessed June 18, 2018).

Zola, David E. 2017. "Toyota Passes Sales Milestone, Plans to Push Affordable Hybrids in the US." Available at https://www.wardsauto.com/engines/toyota-passes-sales-milesto ne-plans-push-affordable-hybrids-us. (accessed September 12, 2018). 